\section{Elegant approach to spacer arranged silagermylene and bis(germylene) compounds $\dagger$}

\author{
Sankaranarayana Pillai Sarish, Sakya S. Sen, Herbert W. Roesky,* Ina Objartel and \\ Dietmar Stalke*
}

Received 17th April 2011, Accepted 6th May 2011

DOI: $10.1039 / \mathrm{c} 1 \mathrm{cc12205c}$

Herein we report on the reactions of the stable $\mathrm{LSiCl}(1)$ and $\mathrm{LGeCl}$ (2) $\left[\mathrm{L}=\operatorname{PhC}(\mathrm{N} t \mathrm{Bu})_{2}\right]$ with $\mathrm{L}^{1} \mathrm{Ge},\left[\mathrm{L}^{1}=\right.$ $\left.\mathrm{CH}\left\{\left(\mathrm{C}=\mathrm{CH}_{2}\right)(\mathrm{CMe})\left(2,6-i \mathrm{Pr}_{2} \mathrm{C}_{6} \mathrm{H}_{3} \mathrm{~N}\right)_{2}\right\}\right]$ (3) to yield 1-sila5-germylene (4) and a 1,5-bis(germylene) (5). The reactions proceed through the 1,4 nucleophilic addition of the $\mathrm{M}-\mathrm{Cl}(\mathrm{M}=\mathrm{Si}$ or $\mathrm{Ge})$ to 3 without any modification of the oxidation state although the change of the oxidation state is thermodynamically more favorable. Compounds 4 and 5 were investigated by single crystal X-ray structural analyses, multi-nuclear NMR spectroscopy, and micro-analysis. Treatment of $\mathrm{L}^{1} \mathrm{AlMe}$-thf (6) with 1 resulted in the formation of the 1-sila-5-aluminium complex (7). The complex contains a $\mathrm{Si}$ (II) and an $\mathrm{Al}$ (III) atom in the molecule. All reported reactions proceed without changing the oxidation states at the metal centers.

Silylenes and germylenes are the silicon and germanium analogues of carbenes and like carbon in carbene, they exhibit the +2 oxidation state. The first stable $N$-heterocyclic silylene was reported by West et al. in $1994,{ }^{1}$ whereas the first $N$-heterocyclic germylene was isolated by Veith and Grosser in $1982 .^{2}$ Since then a number of room temperature stable silylenes ${ }^{3 a-f}$ and germylenes ${ }^{3 g-m}$ were synthesized and structurally characterized. The advent of these compounds opened a fertile research field in main group chemistry with increasing focus towards compounds with two such low valent centers in a single molecule as adjacent elements (Chart 1, type A) or separated by a spacer (Chart 1 , type B).

In type $A$ each $E$ possesses a formal +1 oxidation state whereas in type $\mathrm{B}$ each $\mathrm{E}$ adopts +2 oxidation state. The syntheses, structures, and reactivities of type A have shown a versatile nature. ${ }^{4}$ Previous studies from our laboratory also led to the isolation of bis(silylene) $\left(\mathrm{PhC}(\mathrm{N} t \mathrm{Bu})_{2} \mathrm{Si}\right)_{2}{ }^{5}$ and bis(germylene) $\left(\mathrm{PhC}(\mathrm{N} t \mathrm{Bu})_{2} \mathrm{Ge}\right)_{2}{ }^{6}$ which belong to type $\mathrm{A}$ molecules. Considering the success that type A showed, it seemed appropriate to attempt the synthesis of type B

Institut für Anorganische Chemie, Universität Göttingen,

Tammannstrasse 4, 37077 Göttingen, Germany.

E-mail: hroesky@gwdg.de,dstalke@chemie.uni-goettingen.de;

Fax: + 49 551-39-3373

$\dagger$ Electronic supplementary information (ESI) available: Full synthetic, spectroscopic details for $\mathbf{4}, \mathbf{5}$, and $\mathbf{7}$ and X-ray crystallographic details for 4 and 5. CCDC 819683 and 819684. For ESI and crystallographic data in CIF or other electronic format see DOI: $10.1039 / \mathrm{clcc} 12205 \mathrm{c}$

\author{
LnË-ËLn LnË-X-ËLn \\ type A type B \\ $\mathrm{Ln}=$ monovalent ligand \\ $X=$ spacer \\ $\mathrm{E}=$ homologues of carbon
}

Chart 1 Pictorial diagram of interconnected and spacer separated bis(carbene) analogues.

molecules. There are a few examples of spacer separated bis-silylene $^{7}$ and bis-germylene ${ }^{8}$ known. The synthesis of a compound where two different elements are present in low oxidation states, and each possesses a lone pair of electrons, is of prime interest. Such a goal is definitely challenging and requires a suitable precursor. ${ }^{9}$ The prototypical approach to synthesize type B is to vary the substituents on the nitrogen atom or modify the backbone skeleton of the precursors. ${ }^{7 a, 8 a}$ However, these methods are not appropriate if two different centers have to be present in a single molecule both in low oxidation states. So a different approach is required. Recently, we were successful in isolating a monochloro-silylene $\left(\mathrm{PhC}(\mathrm{N} t \mathrm{Bu})_{2} \mathrm{SiCl}\right) \quad(\mathbf{1})^{10}$ and monochloro-germylene $\left(\mathrm{PhC}(\mathrm{N} t \mathrm{Bu})_{2} \mathrm{GeCl}\right)(\mathbf{2})^{6}$ in high yield. Besides, Driess et al. and we independently isolated a new type of $\mathrm{N}$-heterocyclic-germylene $\mathrm{L}^{1} \mathrm{Ge}\left(\mathrm{L}^{1}=\mathrm{CH}\left\{\left(\mathrm{C}=\mathrm{CH}_{2}\right)(\mathrm{CMe})\left(2,6-i \mathrm{Pr}_{2} \mathrm{C}_{6} \mathrm{H}_{3} \mathrm{~N}\right)_{2}\right\}\right)$ DFT calculation and reactivity patterns divulged that the zwitterionic betaine resonance structure of $\mathbf{3}$ determines its intriguing reactivities. For instance the reaction of $\mathbf{3}$ with trimethylsilyl triflate $\left(\mathrm{Me}_{3} \mathrm{SiOTf}, \mathrm{Tf}=\mathrm{SO}_{2} \mathrm{CF}_{3}\right)$ gives exclusively a 1,4-addition product with the $\mathrm{Me}_{3} \mathrm{Si}$ group at the nucleophilic carbon atom of the terminal methylene moiety and OTf at the electrophilic Ge(II) site. ${ }^{11}$ Now, if we look into the electronic structures of $\mathbf{1}$ and $\mathbf{2}$, they also possess electrophilic $\mathrm{Si}$ and $\mathrm{Ge}$ atoms, respectively, because DFT calculations showed that the lone pair of silylene and germylene becomes concentrated in an orbital that exhibits "s" character. Inspired by these findings we treated 3 with $\mathbf{1}$ and $\mathbf{2}$, respectively, and synthesized a unique silagermylene (4) and a bis(germylene) (5). To the best of our knowledge this is the first example of a spacer separated sila-germylene and a rare example of a spacer separated bis(germylene).

The reactions of $\mathrm{L}^{1} \mathrm{Ge}(3)$ with $\mathrm{LSiCl}(\mathbf{1})$ and $\mathrm{LGeCl}(\mathbf{2}, \mathrm{L}=$ $\left.\mathrm{PhC}(\mathrm{N} t \mathrm{Bu})_{2}\right)$ at room temperature in toluene afford the spacer separated silagermylene complex $\mathbf{4}$ and bis(germylene) complex 


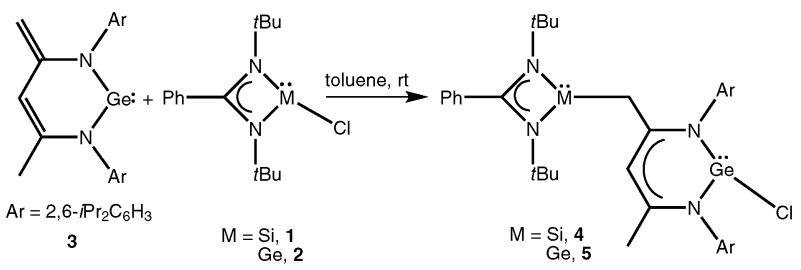

Scheme 1 Syntheses of complexes $\mathbf{4}$ and $\mathbf{5}$.

5 (Scheme 1). 4 is obtained as a yellow crystalline solid in $88 \%$ yield, whereas 5 is isolated in $90 \%$ yield. Both $\mathbf{4}$ and $\mathbf{5}$ show good solubility in common organic solvents such as benzene, toluene, diethyl ether, and THF. The mechanism of the reactions seems to be obvious. In fact, due to the zwitterionic nature of 3 , the electrophilic addition of $\mathrm{LSi}^{+}$or $\mathrm{LGe}^{+}$takes place at the exocyclic methylene group in $\mathbf{3}$, whereas the nucleophile $\mathrm{Cl}^{-}$migrates to the $\beta$-diketiminato $\mathrm{Ge}(\mathrm{II})$ atom. Single crystals of $\mathbf{4}$ for X-ray structural analysis are obtained by storing a solution ( $n$-pentane/toluene) at $-32{ }^{\circ} \mathrm{C}$ in a freezer. 4 crystallizes in the monoclinic space group $P 2_{1} / n$.

The molecular structure of $\mathbf{4}$ is shown in Fig. 1 and the selected bond lengths and angles are listed in the legend of Fig. 1. The amidinate ligand is bonded in a $N, N^{\prime}$-chelating fashion to the $\mathrm{Si}$ atom and displays a distorted tetrahedral geometry (with two nitrogen atoms of the ligand L, the methylene carbon atom of the ligand $\mathrm{L}^{1}$, and the lone pair of electrons at the $\mathrm{Si}$ atom). The four-membered Sil-N1-C1-N2 ring is nearly planar, and the phenyl group is orthogonally arranged to this plane. The Sil-C16 bond (1.9798(19) $\AA$ ) is longer than standard $\mathrm{Si}-\mathrm{C}$ single bonds reported in the literature. ${ }^{13}$ It also indicates that the lone pair at $\mathrm{Si}$ is not involved in multiple bonding and suggests that more $\mathrm{p}$-character is involved in the Si hybrid orbitals which are used for the formation of the $\mathrm{Si}-\mathrm{C}$ bond. The bridging $\mathrm{C} 16$ is

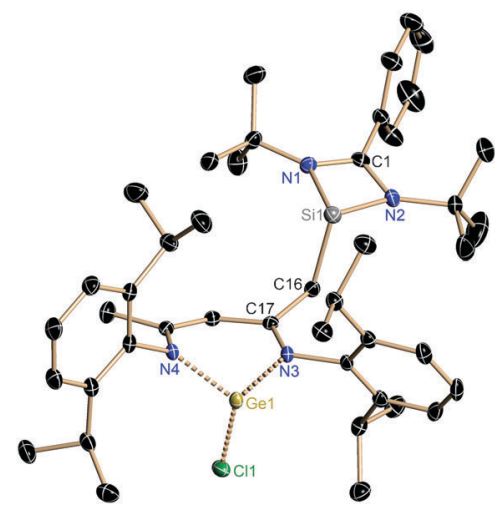

Fig. 1 Molecular structure of 4 . The anisotropic displacement parameters are depicted at the $50 \%$ probability level. All hydrogen atoms are omitted for clarity. Selected bond lengths $(\AA)$ and bond angles $\left(^{\circ}\right)$ : Sil-N1 1.8609(15), Sil-N2 1.8800(17), Si1-C16 1.9798(19), Ge1-N3 1.9832(14), Ge1-N4 1.9467(14), Ge1-Cl1 2.3337(5); N1-Sil-N2 69.31(7), N1-Si1-C16 100.39(8), N2-Si1-C16 95.83(8), N3-Ge1-N4 90.27(6), N4-Ge1-Cl1 96.25(4), N3-Ge1-Cl1 93.03(4). Selected bond lengths $(\AA)$ and bond angles $\left({ }^{\circ}\right)$ for 5: Ge1-N1 1.948(2), Ge1-N2 1.9811(19), Ge1-Cl1 2.3340(7), Ge2-N3 1.988(2), Ge2-N4 2.012(2), Ge2-C29 2.085(2); N1-Ge1-N2 90.42(8), N1-Ge1-Cl1 96.20(6), N2-Ge1-Cl1 93.29(6), N3-Ge2-N4 65.36(8), N4-Ge2-C29 93.52(9), N3-Ge2-C29 97.97(9). also distorted tetrahedrally coordinated. The Ge atom in $\mathbf{4}$ is threefold coordinated and exhibits distorted tetrahedral geometry with the lone pair of electrons (Fig. 1). Two sites are occupied by the chelating nitrogen atoms from the $\beta$-diketiminato ligand with $\mathrm{Ge}-\mathrm{N}$ bond lengths of 1.9467(14) $\AA$

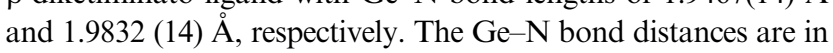
good accordance with those reported in the literature ${ }^{14}$ but slightly longer than those in the precursor 3 (1.8658(17) $\AA$ and $1.8650(18) \AA) .{ }^{11}$ Another site is occupied by the chlorine atom and the lone pair of electrons fill the remaining coordination site of the tetrahedron. The $\mathrm{Ge}-\mathrm{Cl}$ bond length in 4 (2.3337(5) $\AA$ ) matches well with that of $2(2.2572(13) \AA)^{6}$ and $\left[\mathrm{HC}(\mathrm{CMeNAr})_{2}\right] \mathrm{GeCl}\left(\mathrm{Ar}=2,6-i \mathrm{Pr}_{2} \mathrm{C}_{6} \mathrm{H}_{3}\right)(2.295(12) \AA)^{15 a}$ but is significantly longer than that in the recently reported [\{TMSNC(Ph)NTMS $\} \mathrm{GeCl}](2.1556(8) \AA) .{ }^{15 b}$

Single crystals of $\mathbf{5}$ suitable for X-ray structural analysis are obtained from a $n$-pentane/toluene solution stored at $-5{ }^{\circ} \mathrm{C}$ in a freezer for one day. 5 crystallizes in the monoclinic space group $P 2_{1} / n$. Like 4 the coordination environments of each amidinato $\mathrm{Ge}$ atom and $\beta$-diketiminato $\mathrm{Ge}$ atom in $\mathbf{5}$ is threefold coordinated and resides in distorted tetrahedral environments with one vertex occupied by a lone pair of electrons (see ESI $\dagger$ for molecular structure of 5). The amidinato $\mathrm{Ge} 2-\mathrm{C} 29$ bond length $(2.085(2) \AA)$ is $0.08 \AA$ longer than that of $\left[\mathrm{HC}(\mathrm{CMeNAr})_{2}\right] \mathrm{GeMe}\left(\mathrm{Ar}=2,6-i \mathrm{Pr}_{2} \mathrm{C}_{6} \mathrm{H}_{3}\right){ }^{16}$ The bond lengths and angles of the $\mathrm{GeN}_{2} \mathrm{C}$ and $\mathrm{GeN}_{2} \mathrm{C}_{3}$ skeletons in $\mathbf{5}$ are similar to those of $\mathbf{4}$. One interesting feature is the Ge1-Cl1 bond length $(2.3340(7) \AA)$ in 5, which is slightly longer than that in $\left[\mathrm{HC}(\mathrm{CMeNAr})_{2}\right] \mathrm{GeCl}$ $\left(\mathrm{Ar}=2,6-i \mathrm{Pr}_{2} \mathrm{C}_{6} \mathrm{H}_{3}\right)^{15}$ but matches well with that of 4 .

Additionally, $\mathbf{4}$ and $\mathbf{5}$ are characterized by multinuclear NMR spectroscopy, EI-MS spectrometry, and elemental analysis which are in agreement with the constitution of $\mathbf{4}$ and $\mathbf{5}$ as derived from X-ray structural analysis. In the ${ }^{1} \mathrm{H}$ NMR spectra of $\mathbf{4}$ and $\mathbf{5}$ the $t \mathrm{Bu}$ protons appear as two sets of singlets (for 4: $\delta 1.03$ and $0.70 \mathrm{ppm}$ and for 5: $\delta 0.94$ and $0.67 \mathrm{ppm})$. The two non-equivalent $\mathrm{CH}$ protons of the methylene bridge of 4 appear at $\delta 2.79$ and 2.39 ppm and the $\gamma-\mathrm{CH}$ and methyl protons of the $\beta$-diketiminato Ge part resonate as singlets ( $\delta 5.64$ and $\delta 1.84 \mathrm{ppm}$ ). The $\gamma-\mathrm{CH}$ proton of 5 also resonates as a singlet at $\delta 5.64$ ppm like that of 4 . Furthermore, in $\mathbf{5}$ the two non-equivalent $\mathrm{CH}_{2}$ protons of the methylene bridge appear at $\delta 2.88$ and $\delta 2.71 \mathrm{ppm}$, which are shifted downfield compared to those of 4 . In the ${ }^{29} \mathrm{Si}$ NMR spectrum of 4 a resonance exhibits at $\delta 42.45 \mathrm{ppm}$ which corresponds to the three-coordinate silicon atom ${ }^{7 c, 17}$ of 4 and is shifted considerably downfield compared to that of 1 ( $\delta 14.57 \mathrm{ppm}) .{ }^{10}$ The molecular ion peak corresponding to 4 and $\mathbf{5}$ was observed with a relatively low intensity at $m / z 784.5$ and 830.3, respectively, in the EI-mass spectra.

To test the generality of this method we prepared the 1-sila 5-aluminium complex (7) by treatment of 1 with $\mathrm{L}^{1} \mathrm{AlMe} \cdot \mathrm{Mf}$ (6) ${ }^{18}$ in toluene, which afforded a compound containing silicon and aluminium with an oxidation state of +2 and +3 (Scheme 2). The ${ }^{1} \mathrm{H}$ NMR spectrum of 7 exhibits an upfield shifted singlet $(\delta 5.71 \mathrm{ppm})$ compared to $\mathbf{6}(\delta 5.38)$ which can be assigned to the $\gamma-\mathrm{CH}$ proton. The two $\mathrm{CH}_{2}$ protons of the methylene bridge display a resonance at $\delta 2.46 \mathrm{ppm}$. The methyl proton resonances of $\mathrm{Al}-\mathrm{Me}$ and the ligand backbone 


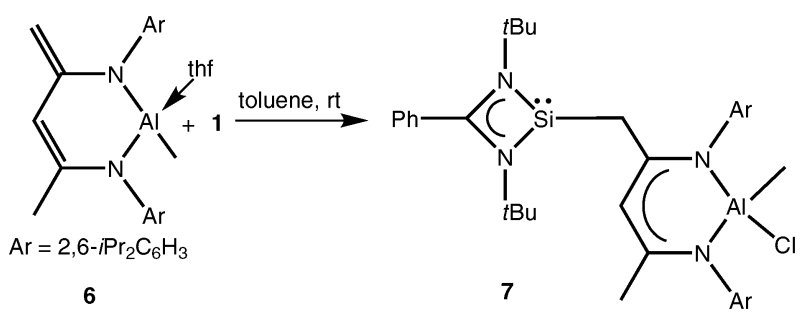

Scheme 2 Syntheses of 7.

emerge downfield ( $\delta-0.50 \mathrm{ppm}$ and $\delta 1.82 \mathrm{ppm})$, when compared with those of $6(\delta-0.99$ and $\delta 1.58 \mathrm{ppm})$. In the ${ }^{13} \mathrm{C}$ NMR spectrum of $7 \mathrm{Al}-\mathrm{Me}$ and $\gamma-\mathrm{C}$ atom of the $\beta$-diketiminato part appear at $\delta-10.8$ and $99.8 \mathrm{ppm}$ respectively. The ${ }^{29} \mathrm{Si}$ NMR spectrum shows a sharp singlet ( $\delta 41.16 \mathrm{ppm}$ ) which corresponds to the three-coordinate silicon atom and also matches excellently with that of 4 . The ${ }^{27} \mathrm{Al} \mathrm{NMR}$ spectrum of 7 is silent due to the quadrupole moment of the aluminium atom. Despite several attempts we are not able to obtain single crystals of 7 .

In summary, complex 4 containing $\mathrm{Si}(\mathrm{II})$ and $\mathrm{Ge}(\mathrm{II})$ has been prepared by the reaction of $\mathbf{1}$ with $\mathbf{3}$. Furthermore, a bis(germylene) $\mathbf{5}$ is also obtained by following the same synthetic protocol. The synthetic strategy was also extended to prepare complex 7 containing a $\mathrm{Si}(\mathrm{II})$ and an $\mathrm{Al}$ (III) center for the first time. This synthetic approach opens an access to Si(II) compounds in combination with other metals excluding the oxidative addition reaction at the $\mathrm{Si}$ (II) center.

This work was supported by the Deutsche Forschungsgemeinschaft. D. S. thanks the DNRF funded Center for Materials Crystallography (CMC) for support and the Land Niedersachsen for providing a fellowship in the Catalysis for Sustainable Synthesis (CaSuS) PhD program.

\section{Notes and references}

1 M. Denk, R. Lennon, R. Hayashi, R. West, A. V. Belyakov, H. P. Verne, A. Haaland, M. Wagner and N. Metzler, J. Am. Chem. Soc., 1994, 116, 2691-2692.

2 M. Veith and M. Grosser, Z. Naturforsch., 1982, 37b, 1375.

3 For recent reviews in silylenes see: (a) M. Haaf, T. Schmedake and R. West, Acc. Chem. Res., 2000, 33, 704-714; (b) N. J. Hill and R. West, J. Organomet. Chem., 2004, 689, 4165-4183; (c) H. Ottosson and P. G. Steel, Chem.-Eur. J., 2006, 12, 1576-1585; (d) M. Kira, Chem. Commun., 2010, 46, 2893-2903; (e) M. Asay, C. Jones and M. Driess, Chem. Rev., 2011, 111, 354-396; (f) S. Yao, Y. Xiong and M. Driess, Organometallics, 2011, 30, 1748-1767; For reviews in germylenes see: $(g)$ M. Veith, Angew. Chem., 1987, 99, 1-14 (Angew. Chem., Int. Ed. Engl., 1987, 26, 1-14); (h) W. P. Neumann, Chem. Rev., 1991, 91, 311-334; (i) H. V. R. Dias, Z. Wang and W. Jin, Coord. Chem. Rev., 1998, 176, 67-86; (j) O. Kühl, Coord. Chem. Rev., 2004, 248, 411-427; (k) I. Saur, S. G. Alonso and J. Barrau, Appl. Organomet. Chem., 2005, 19, 414-428; (l) W.-P. Leung, K.-W. Kan and K.-H. Chong, Coord. Chem. Rev., 2007, 251, 2253-2265; (m) S. Nagendran and H. W. Roesky, Organometallics, 2008, 27, 457-492.
4 (a) P. P. Power, Chem. Rev., 1999, 99, 3463-3503; (b) P. P. Power, Chem. Commun., 2003, 2091-2101; (c) S. P. Green, C. Jones, P. C. Junk, K.-A. Lippert and A. Stasch, Chem. Commun., 2006, 3978-3980; (d) P. P. Power, Organometallics, 2007, 26, 4362-4372; (e) Y. Wang and G. H. Robinson, Chem. Commun., 2009, 5201-5213; $(f)$ R. C. Fischer and P. P. Power, Chem. Rev., 2010, 110, 3877-3923; $(g)$ Y. Peng, R. C. Fischer, W. A. Merrill, J. Fischer, L. Pu, B. D. Ellis, J. C. Fettinger, R. H. Herber and P. P. Power, Chem. Sci., 2010, 1, 461-468.

5 S. S. Sen, A. Jana, H. W. Roesky and C. Schulzke, Angew. Chem., 2009, 121, 8688-8690 (Angew. Chem., Int. Ed., 2009, 48, $8536-8538)$.

6 S. Nagendran, S. S. Sen, H. W. Roesky, D. Koley, H. Grubmüller, A. Pal and R. Herbst-Irmer, Organometallics, 2008, 27, 5459-5463.

7 (a) B. Gehrus, P. B. Hitchcock and M. F. Lappert, Z. Anorg. Allg. Chem., 2005, 631, 1383-1386; (b) H.-X. Yeong, H.-W. Xi, K. H. Lim and C.-W. So, Chem.-Eur. J., 2010, 16, 12956-12961; (c) W. Wang, S. Inoue, S. Yao and M. Driess, J. Am. Chem. Soc., 2010, 132, 15890-15892.

8 (a) F. E. Hahn, A. V. Zabula, T. Pape and A. Hepp, Eur. J. Inorg. Chem., 2007, 2405-2408; (b) S. Yao, X. Zhang, Y. Xiong, H. Schwarz and M. Driess, Organometallics, 2010, 29, 5353-5357; (c) S. S. Sen, D. Kratzert, D. Stern, H. W. Roesky and D. Stalke, Inorg. Chem., 2010, 49, 5786-5788.

9 W. Wang, S. Inoue, S. Yao and M. Driess, Chem. Commun., 2009, 2661-2663.

10 S. S. Sen, H. W. Roesky, D. Stern, J. Henn and D. Stalke, J. Am. Chem. Soc., 2010, 132, 1123-1126.

11 M. Driess, S. Yao, M. Brym and C. van Wüllen, Angew. Chem., 2006, 118, 4455-4458 (Angew. Chem., Int. Ed., 2006, 45, $4349-4352)$.

12 A. Jana, I. Objartel, H. W. Roesky and D. Stalke, Inorg. Chem., 2009, 48, 798-800.

13 (a) S. S. Sen, G. Tavčar, H. W. Roesky, D. Kratzert, J. Hey and D. Stalke, Organometallics, 2010, 29, 2343-2347; (b) M. Kaftory, M. Kapon and M. Botoshansky, The Chemistry of Organic Silicon Compounds, ed. Z. Rappoport and Y. Apeloig, Wiley, Chichester, UK, 1998, vol. 2, ch. 5; (c) S. S. Sen, S. Khan, D. Kratzert, H. W. Roesky and D. Stalke, Eur. J. Inorg. Chem., 2011, 1370-1373; (d) S. Khan, S. S. Sen, D. Kratzert, G. Tavčar, H. W. Roesky and D. Stalke, Chem.-Eur. J., 2011, 17, 4283-4290.

14 (a) M. Veith, S. Becker and V. Huch, Angew. Chem., 1989, 101, 1287-1288 (Angew. Chem., Int. Ed. Engl., 1989, 28, 1237-1238); (b) M. Veith, S. Becker and V. Huch, Angew. Chem., 1990, 102, 186-188 (Angew. Chem., Int. Ed. Engl., 1990, 29, 216-218); (c) M. Veith, A. Detemple and V. Huch, Chem. Ber., 1991, 124, 1135-1141; (d) J. Barrau, G. Rima and T. El Amraoui, J. Organomet. Chem., 1998, 570, 163-174.

15 (a) Y. Ding, H. W. Roesky, M. Noltemeyer, H.-G. Schmidt and P. P. Power, Organometallics, 2001, 20, 1190-1194; (b) D. Matioszek, N. Katir, N. Saffon and A. Castel, Organometallics, 2010, 29, 3039-3046.

16 Y. Ding, Q. Ma, H. W. Roesky, R. Herbst-Irmer, I. Usón, M. Noltemeyer and H.-G. Schmidt, Organometallics, 2002, 21, 5216-5220.

17 C.-W. So, H. W. Roesky, P. M. Gurubasavaraj, R. B. Oswald, M. T. Gamer, P. G. Jones and S. Blaurock, J. Am. Chem. Soc., 2007, 129, 12049-12054.

18 (a) S. P. Sarish, H. W. Roesky, M. John, A. Ringe and J. Magull, Chem. Commun., 2009, 2390-2392; (b) S. P. Sarish, B. Nekoueishahraki, A. Jana, H. W. Roesky, T. Schulz and D. Stalke, Chem.-Eur. J., 2011, 17, 890-894. 